\title{
Reconstruction of the maxilla using a fibula graft and virtual planning techniques
}

\author{
Kristian Rude, ${ }^{1}$ Torben H Thygesen, ${ }^{1}$ Jens Ahm Sørensen ${ }^{2}$
}

${ }^{1}$ Department of Oral and Maxillofacial Surgery, Odense University Hospital, Odense, Denmark

${ }^{2}$ Department of Plastic and Reconstructive Surgery, Odense University Hospital, Odense, Denmark

\section{Correspondence to} Dr Kristian Rude, Kristian_rude@hotmail.com

Accepted 4 April 2014

\section{SUMMARY}

Use of a vascularised free fibula flap has been a popular method of osseous reconstruction because of its adequate length and acceptance of dental implants. In this article we describe a case of maxillary reconstruction in which virtual planning techniques and rapid prototyping were used to insert a microvascular osteomyocutaneous fibula graft, Medpor implant, and immediate dental implants.

\section{BACKGROUND}

A hemimaxillectomy or total maxillectomy causes complex defects in the maxilla, the zygomatic bone, palate, orbital floor, maxillary sinus, alveolar bone and gingiva. These defects can have severe functional and cosmetic consequences. The main aims of reconstructing complex midfacial defects should be: (1) to recreate facial aesthetic appearance and symmetry; (2) to recreate and improve mastication; and (3) to obliterate any communication between the orbit, oral cavity and nasopharynx. Defects have traditionally been managed using a large dental obturative prosthesis, which can be an excellent and definitive treatment for some patients. However for the patient in the present case, the prosthesis was unsatisfactory due to reduced masticatory function, poor aesthetic appearance and poor oral hygiene.

Bone from numerous osseous donor sites, such as the scapula, radius, iliac crest, rib and fibula, has been used for reconstruction of maxillary defects. The free vascularised fibula flap has become the most popular because of its length and acceptance of dental implants. ${ }^{1-6}$

The use of virtual planning and rapid prototyping is increasingly popular in reconstructive surgery, ${ }^{7}$ particularly in complex anatomical reconstructions. Rapid prototyping facilitates the manufacture of three-dimensional (3D) models and templates that allow the surgeon to plan the procedure before surgery, thereby closing the gap between preoperative planning and execution. ${ }^{89}$

This article describes the case of a 15 -year-old girl in whom maxillary reconstructive surgery was performed using virtual planning, rapid prototyping, a free fibula graft and dental implants.

\section{CASE PRESENTATION}

A 15-year-old girl was referred to the Department of Plastic and Reconstructive Surgery and the Department of Oral and Maxillofacial Surgery, Odense University Hospital, Denmark, in 2011 for reconstructive surgery of her right maxilla (figure 1A). In 2007, at the age of 11 the patient had been diagnosed with a large arteriovenous malformation in her right maxilla and had undergone hemimaxillectomy at the Royal Liverpool Children's Hospital NHS Trust, UK. The orbital floor was reconstructed in the same procedure with a calvarial bone graft. The intraoral defect was treated with a removable obturative prosthesis (figure 2A). The patient's main complaints were related to the function and appearance of the prosthesis because of reduced masticatory function and poor oral hygiene. This resulted in a reduced quality of life for the patient.

\section{TREATMENT}

An osseomyocutaneous fibula free flap was planned on the basis of CT of the head and of both legs. A

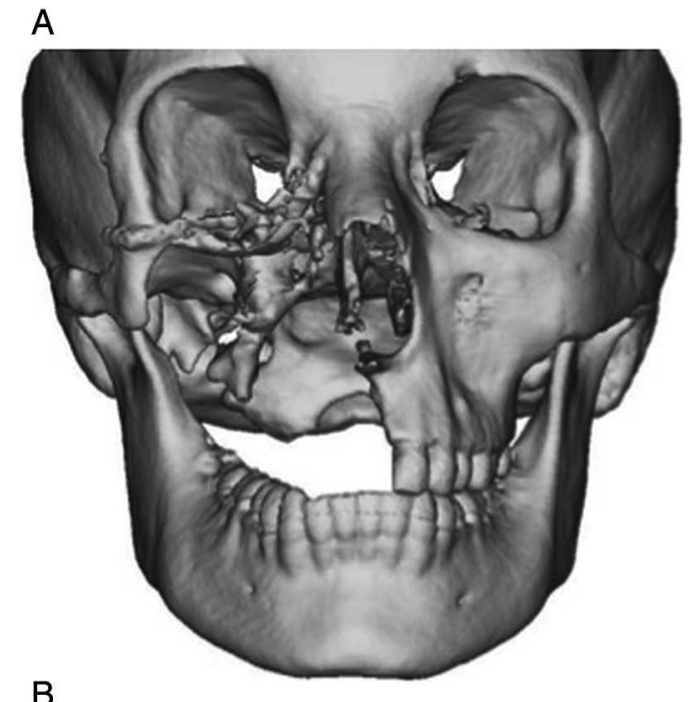

B

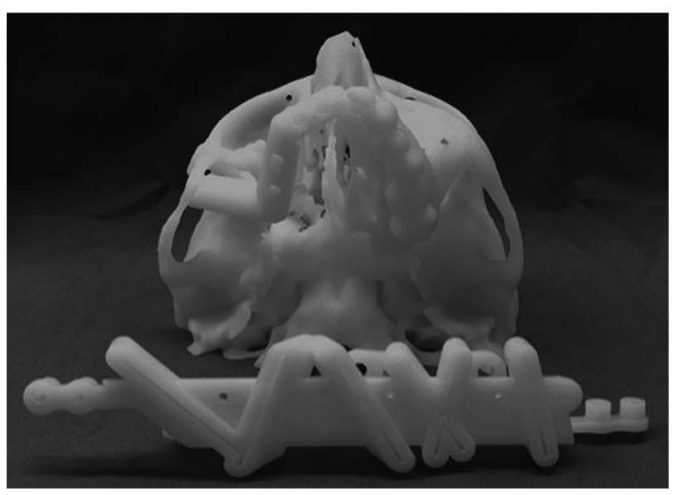

Figure 1 (A) Three-dimensional CT reconstruction visualising the large defect of the right maxilla. (B) Stereo-lithography model with the surgical template for the fibula osteotomies and guided dental implant placement. 


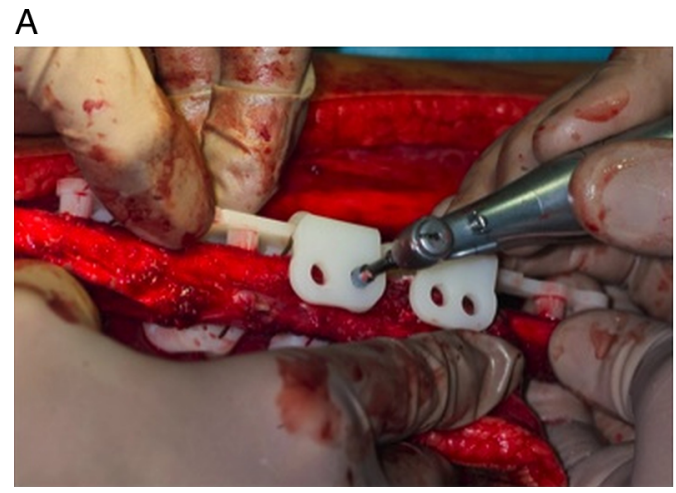

B

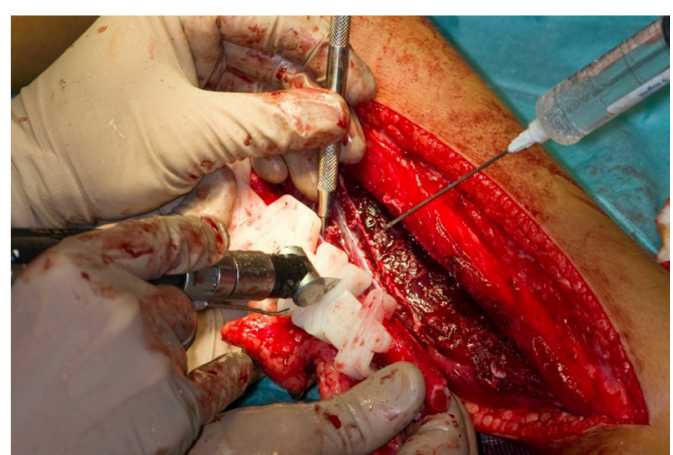

Figure 2 (A) Presurgical obturator prosthesis. (B,C) Oral rehabilitation was carried out using an implant-retained fixed dental prosthesis on three dental implants and coupled to tooth 21 and tooth 22. (D) Facial appearance 12 months after surgery. stereo-lithography (SLA) model was constructed in order to visualise the large defect of the right maxilla and to plan the length and osteotomies of the fibula (figure 1B). A reconstruction plate was made based on the SLA model. The right fibula was found to be the best match for the planned reconstruction. Backward planning was used identify the best position for the free fibula graft: the mandible predefined the ideal position of the implants, which indicated the ideal position of the free fibula graft.

Before surgery, a rapid prototyped template was manufactured (1) to help determine the planned lengths and angles of the fibula osteotomies and (2) to guide the insertion of four dental implants (NobelActive) which were placed in the free fibula graft prior to resection and the planned osteotomies. In addition, a Medpor premanufactured infraorbital implant was planned for insertion to compensate for the patient's infraorbital and zygomatic bony deficiency.

The modified Weber-Ferguson incision was employed during facial surgery. The standard lateral approach as originally described by Gilbert ${ }^{10}$ was used on the right fibula. One sufficiently sized perforator perfusing a skin flap was identified and dissected.

The surgical template was fixed to the fibula using osteosynthesis screws after which the dental implants were inserted. One of the planned implants was abandoned because it was too close to the skin perforator. Finally, the angled osteotomies of the fibula were carried out (figure 3A,B).

The osseomyocutaneous flap was fixed to the premanufactured reconstruction plate and placed in the exact preplanned position at the recipient site and fixed with osteosynthesis
A

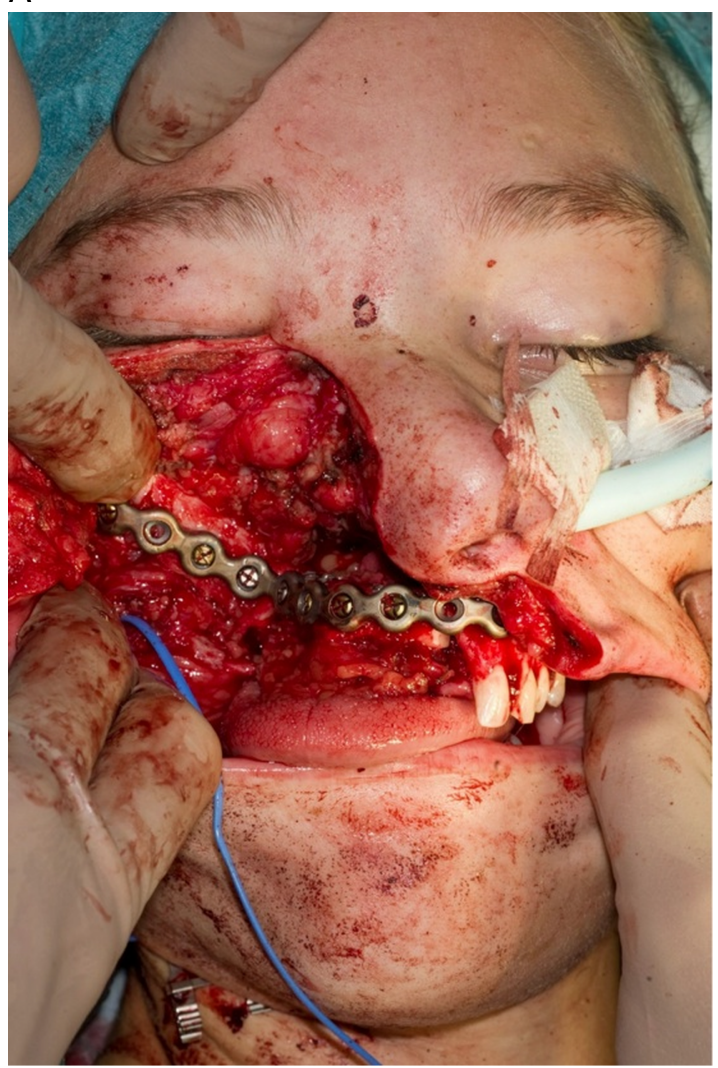

B
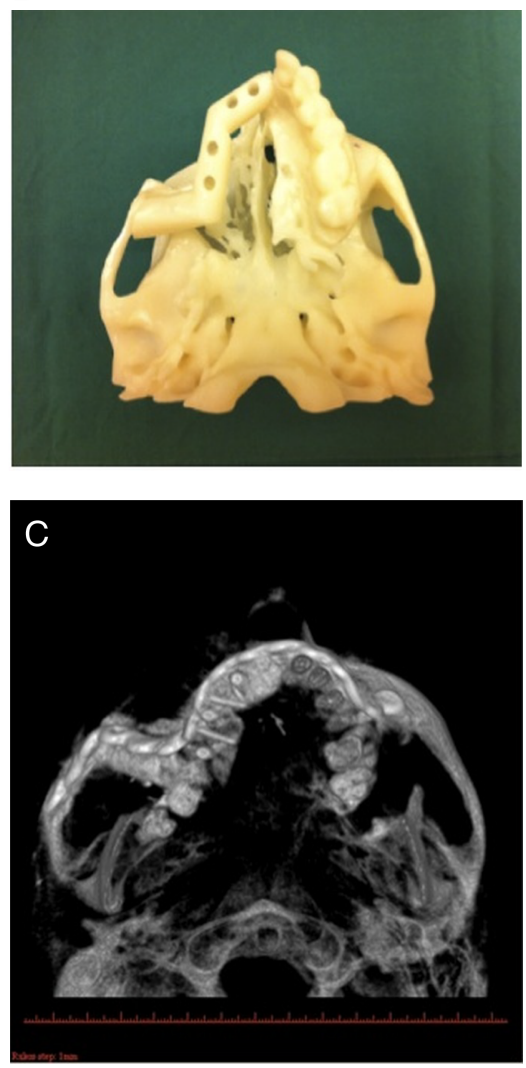

Figure 3 (A) Placement of dental implants using the surgical template. (B) Fibula osteotomies guided by the surgical template. 
screws (figure 4A). The Medpor implant was fixed with two osteosynthesis screws. A vascular pedicle length of $6.5 \mathrm{~cm}$ was insufficient to reach the neck. We did not wish to use the temporal vessels as a temporoparietal flap as had been done in the initial operation because angiography showed insufficient perfusion of the temporal vessels. Therefore, a graft from the great saphenous vein was used for both the artery and the vein which were anastomosed to the facial vessels. Ischaemia time was $138 \mathrm{~min}$. The flap was well perfused, and there were no postoperative problems. The entire skin flap survived completely, but a small necrosis of the scarred mucosa of the palate occurred. The fistula was treated successfully with a small buccal fat pad flap and by mobilising the skin flap.

Prosthodontic treatment was carried out 12 months after surgery, when a fixed dental reconstruction was carried out (figure 2B,C). Orthodontic alignment was also performed in the lower jaw to stabilise the resulting occlusion.

The result was aesthetically refined with fat grafting 10 and 16 months after surgery.

\section{OUTCOME AND FOLLOW-UP}

Transfer of the free fibula graft was successful and uneventful without necrosis, local infections or vessel thrombosis. Donor site morbidity was normal, with only a few complications following surgery. All complications resolved spontaneously over 12 months. The patient did have a small oroantral fistula, which was treated and closed at the time of abutment surgery 10 months postoperatively.

Cone beam CT was performed 1 week after surgery to determine if the fibula has been correctly placed in accordance with the virtually preplanned position (figure 4B,C). There was no evidence of late complications such as plate fracture, implant failure, or loosening of osteosynthesis screws 12 months after surgery.

Oral rehabilitation was carried 12 months postoperatively using an implant-retained fixed dental prosthesis on three dental implants which was coupled to tooth 21 and tooth 22 (figure 2B-D).

\section{DISCUSSION}

The use of the free fibula graft is a well-established technique which has clinical and anatomical advantages, such as adequate bone length and volume in combination with low donor site morbidity and a well-perfused myocutaneous flap. In a systematic review by Ling and Peng, ${ }^{11}$ it was found that one "would expect to pay a low price for free fibula flap surgery with

A

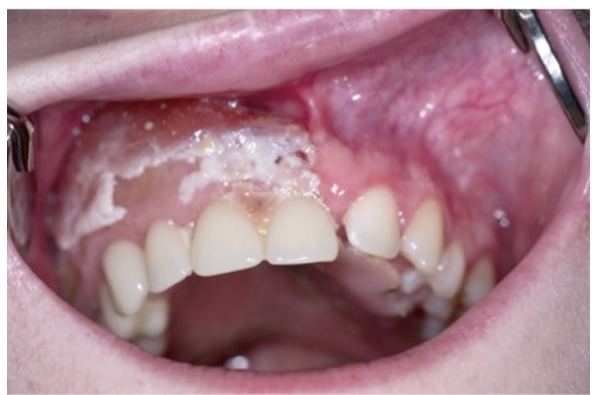

B

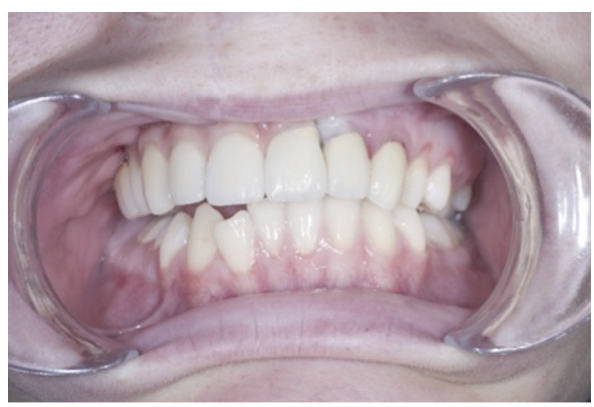

C

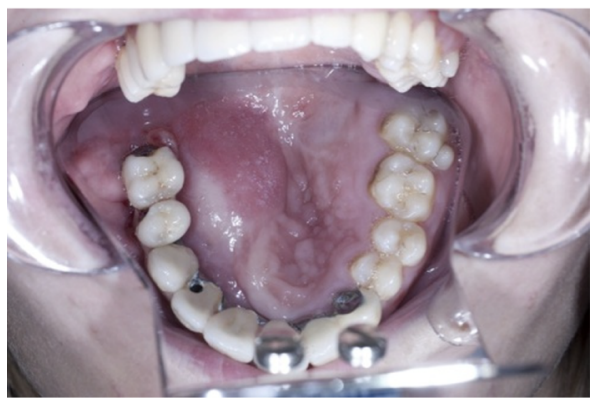

$\mathrm{D}$

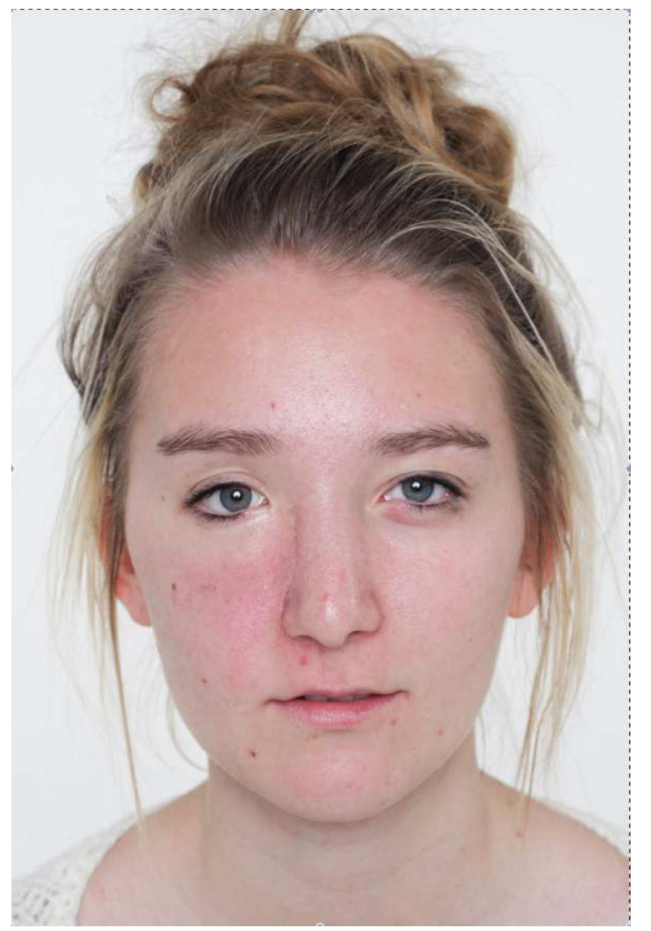

4 (A) Peroperative placement of the osseomyocutaneous flap fixed to the premanufactured reconstruction plate and placed in the exact preplanned position at the recipient site. (B) The virtual preplanned position of the fibula graft. (C) Postoperative cone beam CT showing the accuracy of the fibula placement in accordance with the virtually preplanned position. 
adequate surgical experience, refinements in surgical technique, and comprehensive postoperative care".

The 3D reconstruction of the maxilla is a complex procedure to restore aesthetic appearance and function such as respiration, digestion and speech. These complex reconstructions require a high degree of surgical experience.

Virtual planning and rapid prototyping are a valuable and precise technique for large reconstructions of complicated anatomical sites. ${ }^{12-16}$ Hirsch et $a l^{17}$ and Juergens et $a l^{18}$ both recently presented good results concerning precision and outcome using virtual planning and rapid prototyping in reconstruction of the mandible using a fibula graft.

Virtual planning and rapid prototyping provides: (1) a method to accurately evaluate the anatomy of a defect; (2) optimised presurgical planning; (3) accurate preplanning of osteotomies; (4) optimised fit of the graft without further need for osseous adaption; (5) shortened surgical time; (6) a highly predictable outcome of surgery, as Girod et al have reported; ${ }^{19}$ and (7) improved communication between surgeons and between the surgeon and the patient. Virtual planning and rapid prototyping have few disadvantages, although software is expensive and presurgical planning is time-consuming.

The patient's age of 15 years was initially a concern as there might be further growth of the midface. However, it was decided to carry out definitive treatment as the patient had already had extensive midface surgery at the age of 12 with involvement of growth areas. Furthermore, the patient presented clinically as well developed and hand X-rays showed termination of growth. Should unexpected growth after surgery cause problems with dental rehabilitation, a new implant-retained fixed dental prosthesis could be fitted in compensation.

Accurate assessment of the arterial and venous circulation of the lower extremity before harvesting of a free fibula graft using conventional arteriography and Doppler and eco-colour ultrasound can be difficult. However, modern CT angiography and magnetic resonance angiography has made this assessment much more reliable. ${ }^{20-23}$

The periosteal blood supply is crucial for the altered fibula bone. Quite large segments of the fibula are removed in order to shape the flap into an optimal shape. The periosteum of the resections is carefully dissected from the bone and preserved to maximise blood supply to the bone. Installing dental implants only involves a very small part of the periosteum and the impact on the blood supply is minimal. We abandoned one planned implant because the perforator was too close to the skin flap, a situation which could possibly have been avoided had CT angiography or magnetic resonance angiography been carried out preoperatively. This problem did not affect the final oral rehabilitation of the patient.

\section{Patient's perspective}

The patient was satisfied with the aesthetic and functional results. Donor site morbidity was minimal, and 18 months postoperatively the patient completed a half marathon in less than $2 \mathrm{~h}$.

\section{Learning points}

- Virtual planning and rapid prototyping are a useful and precise technique for large reconstructions of complicated anatomical sites.

- Virtual planning and rapid prototyping provides optimised presurgical planning and a highly predictable surgery outcome.

- Accurate assessment of the arterial and venous circulation of the lower extremity before harvesting of the free fibula graft using CT angiography and magnetic resonance angiography is encouraged.

Acknowledgements The authors thank Arne Eckerdal, DDS, for his great contribution to the dental rehabilitation of this patient.

Contributors KR is the primary and corresponding author. THT and JAS planned/ carried out the operation and reviewed the article.

Competing interests None.

Patient consent Obtained.

Provenance and peer review Not commissioned; externally peer reviewed.

\section{REFERENCES}

1 Hidalgo DA. A new method of mandible reconstruction. Plast Reconstr Surg 1989;84:71.

2 Hidalgo DA, Rekow A. A review of 60 consecutive fibula free flap mandible reconstructions. Plast Reconstr Surg 1995;96:585.

3 Wei FC, Chen HC, Chaung CC, et al. Fibula osteoseptocutaneous flap: anatomic study and clinical application. Plast Reconstr Surg 1986;78:191.

4 Foster RD, Anthony JP, Sharma A, et al. Vascularized bone flaps versus nonvascularized bone grafts for mandibular reconstruction: an outcome analysis of primary bony union and endosseous implant success. Head Neck 1999;21:66.

5 Schusterman MA, Miller MJ, Reece GP, et al. A single center's experience with 308 free flaps for repair of head and neck cancer defects. Plast Reconstr Surg 1994;93:472.

6 Gbara A, Darwich K, Li L, et al. Long-term results of jaw reconstruction with microsurgical fibula grafts and dental implants. J Oral Maxillofac Surg 2007;65:1005-9.

7 Olszewski R. Surgical engineering in cranio-maxillofacial surgery: A literature review. J Healthc Eng 2012;3:53-86.

8 Altobelli DE, Kikinis R, Mulliken JB, et al. Computer-assisted three-dimensional planning in craniofacial surgery. Plast Reconstr Surg 1993;92:576.

9 Antony AK, Chen WF, Kolokythas A, et al. Use of virtual surgery and stereolithography-guided osteotomy for mandibular reconstruction with the free fibula. Plast Reconstr Surg 2011;128:1080.

10 Gilbert A. Free transfer of the fibula shaft. Int J Microsurg 1979;2:100-6.

11 Ling XF, Peng $X$. What is the price to pay for a free fibula flap? A systematic review of donor-site morbidity following free fibula flap surgery. Plast Reconstr Surg 2012:129:657-74.

12 Metzger MC, Hohlweg-Majert B, Schon R, et al. Verification of clinical precision after computer-aided reconstruction in craniomaxillofacial surgery. Oral Surg Oral Med Pathol Oral Radiol Endod 2007;104:e1-10.

13 Modabber A, Legros C, Rana M, et al. Evaluation of computer-assisted jaw reconstruction with free vascularized fibular flap compared to conventional surgery: a clinical pilot study. Int J Med Robotics Comput Assist Surg 2012;8:215-20.

14 Liu XJ, Gui L, Mao C, et al. Applying computer techniques in maxillofacial reconstruction using a fibula flap: a messenger and an evaluation method. J Craniofac Surg 2009;20:372.

15 Foley BD, Thayer WP, Honeybrook A, et al. Mandibular reconstruction using computer-aided design and computer-aided manufacturing: an analysis of surgical results. J Oral Maxillofac Surg 2013;71:e111-9.

16 Tucker S, Cevidanes LH, Styner M, et al. Comparison of actual surgical outcomes and 3-dimensional surgical simulations. J Oral Maxillofac Surg 2010;68:2412.

17 Hirsch DL, Garfein ES, Christensen A, et al. Use of computer-aided design and computer-aided manufacturing to produce orthognathically ideal surgical outcome: 
a paradigm shift in head and neck reconstruction. J Oral Maxillofac Surg 2009;67:2115-22.

18 Juergens $\mathrm{P}, \mathrm{Krol} \mathrm{Z}$, Zeilhofer $\mathrm{HF}$, et al. Computer simulation and rapid prototyping for the reconstruction of the mandible. J Oral Maxillofac Surg 2009;67:2167-70.

19 Girod S, Teschner M, Schrell U, et al. Computer-aided 3-D simulation and prediction of craniofacial surgery: a new approach. J Craniomaxillofac Surg 2001;29:156-8.

20 Ribuffo D, Atzeni M, Saba L, et al. Clinical study of peroneal artery perforators with computed tomographic angiography: implications for fibula flap harvest. Surg Radiol Anat 2010;32:329-34.
21 Karanas YL, Antony A, Rubin G, et al. Preoperative CT angiography for free fibula transfer. Wiley InterScience, 2004. http://www.interscience.wiley.com (accessed 23 Apr 2014).

22 Hölzle F, Ristow 0, Mücke T, et al. Evaluation of the vessels of the lower leg before microsurgical fibular transfer. Part II: magnetic resonance angiography for standard preoperative assessment. Br J Oral Maxillofac Surg 2011:49:275-80

23 Fukaya $E$, Saloner $D$, Leon $P$, et al. Magnetic resonance angiography to evaluate septocutaneous perforators in free fibula flap transfer. J Plast Reconstr Aesthet Surg 2010:63:1099-104.

Copyright 2014 BMJ Publishing Group. All rights reserved. For permission to reuse any of this content visit

http://group.bmj.com/group/rights-licensing/permissions.

BMJ Case Report Fellows may re-use this article for personal use and teaching without any further permission.

Become a Fellow of BMJ Case Reports today and you can:

- Submit as many cases as you like

- Enjoy fast sympathetic peer review and rapid publication of accepted articles

- Access all the published articles

- Re-use any of the published material for personal use and teaching without further permission

For information on Institutional Fellowships contact consortiasales@bmjgroup.com

Visit casereports.bmj.com for more articles like this and to become a Fellow 